\title{
A familial case of pulmonary arterial sequestration
}

\author{
J D Dyer, J M Anderson, P R John
}

\begin{abstract}
The cases of a mother and infant son are reported, both with a rare type of pulmonary sequestration where the arterial supply to the lung arises from the systemic circulation. This is a familial case of arterial sequestration. In both patients, the lung parenchyma was radiologically normal.
\end{abstract}

(Arch Dis Child 2000;82:148-149)

Keywords: pulmonary arterial sequestration; haemoptysis; Scimitar syndrome

A previously well woman had her first haemoptysis at 19 years old. Chest $x$ ray and ventilation perfusion lung scan at presentation were normal. A provisional diagnosis of tracheitis was made. She re-presented with haemoptysis five years later in the second trimester of her second pregnancy. Bronchoscopy showed a large clot in the bronchus intermedius and right lower lobe bronchus. Throughout the third trimester recurrent haemoptysis became increasingly frequent and continued after delivery. A computed tomography (CT) scan of her thorax showed an anomalous artery from below the diaphragm supplying the right lung base and pulmonary angiography showed absence of a pulmonary arterial supply to the postero-basal segment of the right lower lobe. An aortogram was not performed.

Twelve months later she had further haemoptyses. Aortography revealed an anomalous artery arising from the coeliac axis supplying the posterio-basal segment of the right lower lobe (fig 1). Venous drainage from this area entered the left atrium. The diagnosis of pulmonary artery sequestration was estab-

Department,

Birmingham

Heartlands Hospital,

Bordesley Green East, Birmingham, B9 5ST,

UK

J D Dyer

Paediatric

Department, New

Cross Hospital,

Wolverhampton

WV10 0PQ, UK

$\mathrm{J} M$ Anderson

\section{Radiology \\ Department, \\ Birmingham \\ Children's Hospital, \\ Birmingham B4 6NH, \\ UK \\ P R John}

Correspondence to: Dr J D Dyer, X Ray

Department, Scarborough

Hospital, Scarborough YO12 6QL, UK

Accepted 14 September 1999

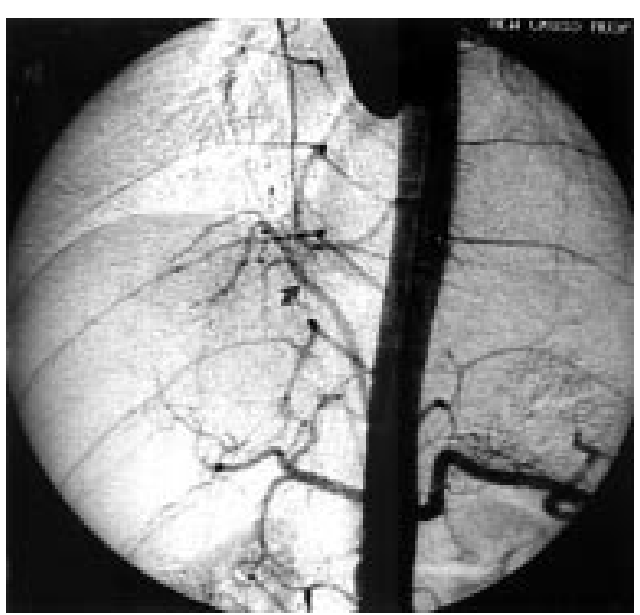

Figure 1 Mother's aortogram showing the anomalous system arterial supply to the right lung base from the coeliac axis (arrow). Its location is identical to her son's vessel. lished with sequestration of the right lower lobe from its normal pulmonary artery supply.

At thoracotomy, an enlarged anomalous artery was found along the right side of the oesophagus and the free edge of the right pulmonary ligament. Histology of the excised lung showed changes of local severe prolonged pulmonary hypertension.

Her second son was born at 37 weeks' gestation. A patent ductus arteriosus (PDA) was diagnosed at his first neonatal examination when he was tachypnoeic with an enlarged liver. The PDA was confirmed by echocardiography. He remained dyspnoeic during feeding, suffered frequent respiratory tract infections, and was failing to thrive, with a body weight on the third centile. His chest $x$ ray showed cardiomegaly with clear lungs.

Angiography was performed with a view to closing the PDA. During this study, an anomalous artery arising from the coeliac axis was seen supplying the right lower lobe, which drained into the left atrium (fig 2). The anomalous vessel was coil embolised resulting in a partial occlusion. The PDA was closed completely.

On follow up, he continued to have frequent respiratory tract infections and his body weight remained on the third centile. Repeat angiography at 16 months of age showed complete occlusion of the anomalous systemic feeding artery. Presently, aged 3 years, he remains well.

\section{Discussion}

Embryologically, pulmonary sequestration results from anomalies of foregut budding in which pulmonary tissue can be sequestered from the bronchial tree (bronchial sequestration) and/or the pulmonary arterial circulation (pulmonary arterial sequestration). ${ }^{12}$ In this

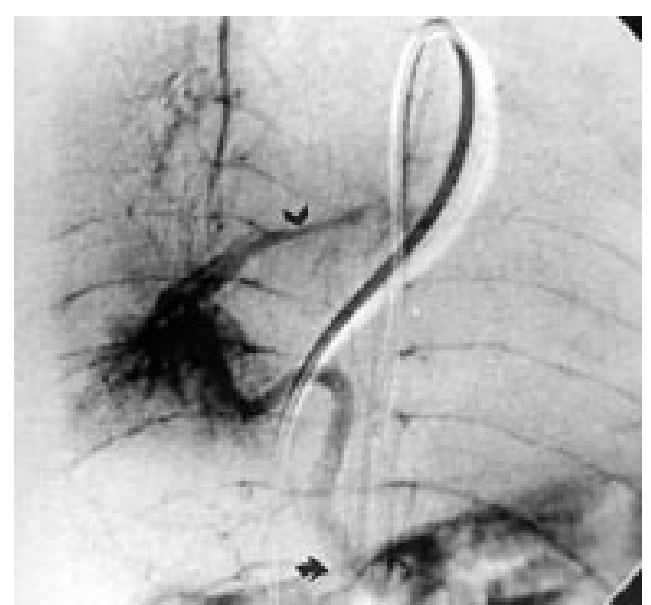

Figure 2 Infant aortogram showing the anomalous systemic arterial supply to the right lung base from the coeliac axis (curved arrow) with venous drainage to the left atrium (arrow head). 
familial case with isolated pulmonary arterial sequestration, the lung receives an anomalous arterial supply from the systemic circulation and there are no parenchymal lung changes evident on chest $x$ ray or CT scan. It is known that most isolated pulmonary artery sequestrations in infancy are found at angiographic investigation for congenital heart disease or anomalous pulmonary venous drainage anomalies. $^{3}$

Familial cases of pulmonary sequestration are rare. With only three reports to date, two in association with the Scimitar syndrome (right lung hypoplasia, cardiac dextraposition, and a systemic arterial supply and venous drainage) in a father and daughter and a father and son, ${ }^{45}$ and one in siblings from consecutive pregnancies. ${ }^{6}$ In the affected sibling case a combined bronchial and pulmonary arterial sequestration was present, with the anomalous systemic feeding artery arising from the descending thoracic aorta. The lung parenchyma was abnormal on ultrasound and chest $x$ ray. A PDA was present in one of the siblings.
Our report adds to the exceptionally rare description of familial pulmonary sequestration. Familial isolated pulmonary arterial sequestration, as we present here, has not been described previously.

Thanks to Miss C Beet and Miss A Stephen for typing this paper.

1 Sade RM, Clouse M, Ellis FH. The spectrum of pulmonary sequestration. Ann Thorac Surg 1974;18:644.

2 Thilenus OG, Rushiaput DG, Replogie RL, Bharatid S, Herman T, Archilla RA. Spectrum of pulmonary sequestration: association with anomalous pulmonary venous drainage in infants. Pediatr Cardiol 1983;4:97.

3 John PR, Beasley SW, Mayne V. Pulmonary sequestration and related congenital disorders. Pediatr Radiol 1989;20:4-9.

4 Neill CA, Ferencz C. The familial occurrence of hypoplastic right lung with systemic arterial supply and venous drainage "Scimitar syndrome". Bulletin of the fohns Hopkins Hospital 1960;107:1-21.

5 Trinca M, Rey C, Breviere GM. Le syndrome du cimeterre a forme familiale. Arch Mal Coeur Vaiss 1993;86:635-8.

6 Abuhamad AZ, Bass T, Katz ME, Heyl PS. Familial recurrence of pulmonary sequestration. Obstet Gynecol 1996;87: 843-5. 